Article

\title{
Determination of Delafloxacin in Pharmaceutical Formulations Using a Green RP-HPTLC and NP-HPTLC Methods: A Comparative Study
}

\author{
Prawez Alam ${ }^{1}$, Essam Ezzeldin ${ }^{2,3}$, Muzaffar Iqbal ${ }^{2,3}$, Gamal A.E. Mostafa ${ }^{2,4}$, \\ Md. Khalid Anwer ${ }^{5}$, Mohammed H. Alqarni ${ }^{1}$, Ahmed I. Foudah ${ }^{1}$ and Faiyaz Shakeel ${ }^{6, *}$ (D) \\ 1 Department of Pharmacognosy, College of Pharmacy, Prince Sattam Bin Abdulaziz University, \\ Al-Kharj 11942, Saudi Arabia; p.alam@psau.edu.sa (P.A.); m.alqarni@psau.edu.sa (M.H.A.); \\ a.foudah@psau.edu.sa (A.I.F.) \\ 2 Department of Pharmaceutical Chemistry, College of Pharmacy, King Saud University, Riyadh 11451, \\ Saudi Arabia; ezzeldin24@hotmail.com (E.E.); muziqbal@gmail.com (M.I.); \\ gamal_most@yahoo.com (G.A.E.M.) \\ 3 Drug Bioavailability Unit, Central Laboratory, College of Pharmacy, King Saud University, P.O. Box 2457, \\ Riyadh 11451, Saudi Arabia \\ 4 Micro-Analytical Laboratory, Applied Organic Chemistry Department, National Research Center, Dokki, \\ Cairo 12622, Egypt \\ 5 Department of Pharmaceutics, College of Pharmacy, Prince Sattam Bin Abdulaziz University, Al-Kharj 11942, \\ Saudi Arabia; mkanwer2002@yahoo.co.in \\ 6 Department of Pharmaceutics, College of Pharmacy, King Saud University, Riyadh 11451, Saudi Arabia \\ * Correspondence: fsahmad@ksu.edu.sa
}

Received: 2 June 2020; Accepted: 22 June 2020; Published: 25 June 2020

\begin{abstract}
In this work; delafloxacin (DLFX) was determined using a validated green RP-HPTLC and NP-HPTLC methods in commercial tablets and in-house developed solid lipid nanoparticles (SLNs). RP-HPTLC determination of DLFX was performed using "RP-18 silica gel 60 F254S HPTLC plates". However; NP-HPTLC estimation of DLFX was performed using "silica gel 60 F254S HPTLC plates". For a green RP-HPTLC method; the ternary combination of ethanol:water:ammonia solution $(5: 4: 2 v / v / v)$ was used as green mobile phase. However; for NP-HPTLC method; the ternary mixture of ethyl acetate: methanol: ammonia solution $(5: 4: 2 v / v / v)$ was used as normal mobile phase. The analysis of DLFX was conducted in absorbance/reflectance mode of densitometry at $\lambda_{\max }=295 \mathrm{~nm}$ for both methods. RP-HPTLC method was found more accurate, precise, robust and sensitive for the analysis of DLFX compared with the NP-HPTLC method. The \% assay of DLFX in commercial tablets and in-house developed SLNs was determined as 98.2 and 101.0\%, respectively, using the green RP-HPTLC technique, however; the \% assay of DLFX in commercial tablets and in-house developed SLNs was found to be 94.4 and $95.0 \%$, respectively, using the NP-HPTLC method. Overall, the green RP-HPTLC method was found superior over the NP-HPTLC. Therefore, the proposed green RP-HPTLC method can be successfully applied for analysis of DLFX in commercial tablets, SLNs and other formulations containing DLFX.
\end{abstract}

Keywords: delafloxacin; green RP-HPTLC; NP-HPTLC; ICH guidelines; solid lipid nanoparticles

\section{Introduction}

Delafloxacin (DLFX) is a novel fluoroquinolone antibiotic which was approved by the US FDA in 2017 [1,2] for the treatment of "acute bacterial skin and skin structure infections (ABSSSIs)" [3,4]. It has also been found effective for the treatment of community-acquired respiratory tract infections 
(CARTIs) [4,5]. It is under clinical trial for CARTIs treatment [5]. It has been reported active against major microbes responsible for ABSSSIs and CARTIs [6,7]. It is rapidly absorbed following oral administration with peak plasma levels obtained within 1-2.5 $\mathrm{h}[8,9]$. The absolute bioavailability of DLFX was found to be very low $(58.8 \%)$ which was probably due to its poor solubility in aqueous media such as water [10]. A literature survey revealed a single derivative spectroscopic method for the determination of DLFX in bulk materials and laboratory prepared mixtures [11]. A single "ultra-high performance liquid chromatography tandem mass spectrometry/mass spectrometry (UHPLC-MS/MS)" method has also been reported for the estimation of DLFX in rat plasma and rabbit aqueous humour but not in pharmaceutical dosage forms [10]. However, the cost and maintenance of more robust and reliable apparatus such as "UHPLC-MS/MS" apparatus is very high compared with "high-performance thin layer chromatography (HPTLC)". Moreover, highly-skilled trained personnel are required to operate "UHPLC-MS/MS" apparatus compared with HPTLC [10,12]. Recently, a HPTLC method has been reported for the estimation of DLFX in human plasma and its pharmacokinetic assessment in real plasma samples of rats [12]. Although, the reported HPTLC method was validated for the estimation of DLFX in biological samples, it was not applied to real pharmaceutical formulation samples [12]. Some clinical reports are also available for the assessment of pharmacokinetic profile of DLFX in healthy human subjects and diseased patients but these clinical reports have not disclosed any information about method development and validation [13-15]. To the best of our knowledge, not a single HPTLC method has been applied for the determination of DLFX in its pure form and pharmaceutical formulations. Pharmaceutical analysis laboratories and pharmaceutical industries are using huge number of toxic solvents such as acetonitrile, methanol and chloroform etc. either alone or in combination for pharmaceutical and bioanalytical procedures which causes the significant problems to the environment due to their environmental toxicity [16]. In addition, the environmental effects of analytical and bioanalytical procedures have been either neglected or little attention has been paid towards such analysis $[16,17]$. In recent years, mentions in the literature of analytical and bioanalytical procedures related with "green analytical chemistry or environmentally-benign analytical methods' have increased significantly [18-22]. In spite of their various beneficial characteristics, including "non-toxicity, non-volatility, non-inflammability, non-aggressiveness, high biodegradability and cost effectiveness", the full potential of green solvents had not been utilized fully as the mobile phase for HPTLC estimation of drugs/pharmaceuticals [23-25].

Green HPTLC techniques offer several advantages compared with conventional HPTLC techniques in pharmaceutical/biomedical analysis [26-30]. Therefore, in this research; DLFX was estimated using a green reversed phase HPTLC (RP-HPTLC) method in commercial tablets and in-house developed solid lipid nanoparticles (SLNs). For comparison purposes, DLFX was also quantified in commercial tablets and in-house developed SLNs using a normal phase HPTLC (NP-HPTLC) method. In general, green analytical methods suffer sensitivity problems in pharmaceutical analysis compared with routine analytical techniques $[16,17]$. In order to compare various validation parameters of the proposed green RP-HPTLC technique, the NP-HPTLC method was also used as a standard method for the estimation of DLFX. Both green RP-HPTLC and NP-HPTLC methods were validated in terms of linearity, accuracy, precision, robustness and sensitivity according to the "International Conference on Harmonization (ICH)" Q2 (R1) guidelines [31].

\section{Materials and Methods}

\subsection{Materials Used}

DLFX was procured from Beijing Mesochem Technology Pvt. Ltd. (Beijing, China). Chitosan (CS) and stearic acid (SA) were acquired from Sigma Aldrich (St. Louis, MO, USA). Chromatography grades solvents (i.e., methanol, ethanol and ethyl acetate), ammonia solution (30\% v/v) and glacial acetic acid were obtained from E. Merck (Darmstadt, Germany). Pluronic F-127 was obtained from BASF (Ludwigshafen, Germany). Deionized water was collected from a Milli-Q unit. Commercial 
tablets of DLFX were obtained from a pharmacy in Riyadh, Saudi Arabia. All other solvents and reagents were of analytical reagent grades.

\subsection{Preparation of Stock Slutions and DLFX Calibration Curve}

Standard stock solution (SSS) of DLFX was obtained by dissolving an accurately weighed $10 \mathrm{mg}$ sample of DLFX in $10 \mathrm{~mL}$ of methanol. Around $1 \mathrm{~mL}$ of SSS of DLFX was further diluted with mobile phase in order to obtain the final SSS of $100 \mu \mathrm{g} / \mathrm{mL}$. Different volumes of SSS $(100 \mu \mathrm{g} / \mathrm{mL})$ were taken and serial dilutions were made in order to obtain concentrations in the range of 25-1000 and 50-600 ng/band of DLFX for RP-HPTLC and NP-HPTLC, respectively. These concentrations of DLFX were spotted on TLC plates and the peak area of DLFX for each concentration was recorded for both methods. The calibration curve (CC) of DLFX was constructed between the concentration and measured area for both methods. The CC for a green RP-HPTLC method was obtained in the range of $25-1000 \mathrm{ng} / \mathrm{band}$. However, the CC for a NP-HPTLC method was obtained in the range of $50-600 \mathrm{ng} / \mathrm{band}$.

\subsection{Sample Preparation for the Analysis of DLFX in Commercial Tablets}

Ten commercial tablets (each tablet containing $450 \mathrm{mg}$ of DLFX) were taken, weighed and the average weight was determined. The tablets were crushed and a fine powder was obtained. A weighed sample of the fine powder containing $50 \mathrm{mg}$ of DLFX was dissolved in methanol and diluted with mobile phase in order to obtain $100 \mathrm{~mL}$ stock solution (SS) for both methods. This SS was filtered to eliminate any insoluble substance and sonicated for about $10 \mathrm{~min}$. Around $1.0 \mathrm{~mL}$ of this SS of commercial tablets was diluted further with $10 \mathrm{~mL}$ of mobile phase for both methods. The diluted SS was taken for the analysis of DLFX content in commercial tablets using RP-HPTLC and NP-HPTLC methods.

\subsection{Preparation of and Characterization DLFX-Loaded SLNs}

DLFX-loaded SA-CS-SLNs were prepared by applying a "single emulsion solvent evaporation method" [32]. In the preparation of SLNs, SA, Pluronic F-127 and CS were used as lipid, surfactant and polymer, respectively. The organic phase was obtained by dissolving $400 \mathrm{mg}$ of SA in $2 \mathrm{~mL}$ of ethyl acetate. An accurately weighed $10 \mathrm{mg}$ sample of DLFX was dissolved in $2 \mathrm{~mL}$ of organic phase i.e., SA solution in ethyl acetate. The aqueous phase was prepared by dissolving $10 \mathrm{mg}$ of CS in $1 \% w / v$ aqueous acetic acid solution $(1 \mathrm{mg} / \mathrm{mL})$ containing $50 \mathrm{mg}$ of Pluronic F-127. The organic and aqueous phases were emulsified for about $3 \mathrm{~min}$ at $60 \%$ voltage efficiency with the help of a probe sonicator (Ultrasonic Processor, gx-130, Berlin, Germany) at $25^{\circ} \mathrm{C}$. The volatile organic solvent was evaporated by magnetic stirrer at $40^{\circ} \mathrm{C}$ for overnight. After complete evaporation of ethyl acetate, DLFX-loaded SA-CS-SLNs were separated from the bulk aqueous phase using high speed centrifugation (Hermle Labortechnik, Wehingen, Germany) at 10,500 $\mathrm{g}$ for about $30 \mathrm{~min}$ followed by three times washing with cold distilled water and finally freeze dried using a Freeze Dryer (Millirock Technology, Kingston, NY, USA). DLFX-loaded SA-CS-SLNs were characterized in terms of particle size, polydispersity index, zeta potential and entrapment efficiency [32].

\subsection{Sample Preparation for Determination of DLFX in In-House Developed SLNs}

Approximately $250 \mathrm{mg}$ of in-house developed SLNs (containing $50 \mathrm{mg}$ of DLFX) were dissolved in methanol and diluted with mobile phase in order to obtain $50 \mathrm{~mL} \mathrm{SS}$ for both methods. The SS of DLFX was filtered in order to eliminate insoluble materials and sonicated for about $10 \mathrm{~min}$. About $1.0 \mathrm{~mL}$ of above SS was further diluted with $10 \mathrm{~mL}$ of mobile phase for both methods. The diluted SS was subjected for the estimation of DLFX in in-house developed SLNs using green RP-HPTLC and NP-HPTLC methods. 


\subsection{Instrumentation and Analytical Conditions}

For the determination of DLFX by green RP-HPTLC and NP-HPTLC methods, the following instrumentation and analytical conditions were applied:

HPTLC instrument: CAMAG TLC system (Muttenz, Basel-landschaft, Switzerland)

Software: WinCAT (version 1.4.3.6336)

Syringe for sample application: CAMAG microliter Syringe (Hamilton, Bonaduz, Switzerland)

TLC plates: $10 \times 20 \mathrm{~cm}$ glass backed plates pre-coated with RP-18 silica gel 60 F254S plates

(E-Merck, Darmstadt, Germany) for RP-HPTLC method and $10 \times 20 \mathrm{~cm}$ glass backed plates pre-coated with silica gel 60 F254S plates (E. Merck) for NP-HPTLC method

Sample applicator: CAMAG Linomat-V

Gas for sample application: Nitrogen

Development chamber: CAMAG automatic developing chamber 2 (ADC2)

TLC scanner: CAMAG TLC scanner-III

Stationary phase: $10 \times 20 \mathrm{~cm}$ glass backed plates pre-coated with RP-18 silica gel $60 \mathrm{~F} 254 \mathrm{~S}$ plates

(E. Merck) for the RP-HPTLC method and $10 \times 20 \mathrm{~cm}$ glass backed plates pre-coated with silica gel 60 F254S plates (E. Merck) for the NP-HPTLC method

Mobile phase for a green RP-HPTLC method: ethanol:water:ammonia solution (5:4:2 v/v/v)

Mobile phase for NP-HPTLC method: Ethyl acetate: methanol: ammonia solution (5:4:2 v/v/v)

Saturation time of mobile phase: $30 \mathrm{~min}$ at $22^{\circ} \mathrm{C}$

Development distance on plate: $80 \mathrm{~mm}$

Development mode: Linear ascending mode

Sample application rate: $150 \mathrm{~nL} / \mathrm{s}$

Densitometry of scanning mode: Absorbance/reflectance.

Scanning wavelength of APM: $295 \mathrm{~nm}$

\subsection{Analytical Method Validation}

Both green RP-HPTLC and NP-HPTLC methods for the determination of DLFX were validated in terms of "linearity, precision, accuracy, robustness, sensitivity and specificity" as per ICH Q2 (R1) guidelines [31]. The linearity of DLFX was determined by plotting the concentration of DLFX against the measured HPTLC area of DLFX. Linearity was found out in the concentration range of 25-1000 ng/band and 50-600 ng/band for the RP-HPTLC and NP-HPTLC, respectively. The method accuracy was found out as the percent of recovery (\% recovery) at four different concentrations of DLFX. As the linearity range was different for NP-HPTLC and RP-HPTLC methods, the studied concentrations for accuracy measurement were different for both methods. For the RP-HPTLC method, the $\%$ recovery of DLFX was estimated at four different concentrations $(75,300,400$ and $500 \mathrm{ng} / \mathrm{band})$. However, for the NP-HPTLC method, the \% recovery was estimated at four different concentrations of 150, 300, 400 and $500 \mathrm{ng} / \mathrm{band}$. The studied concentrations for accuracy measurements were selected as per ICH guidelines [31].

Method precision was measured as repeatability and intermediate precision. Repeatability, i.e., intra-day precision, was determined by the analysis of samples on the same day at 75,300 and $400 \mathrm{ng} / \mathrm{band}$ concentrations $(n=6)$ of DLFX for the RP-HPTLC method. The repeatability of the NP-HPTLC method was determined at 150, 300 and $400 \mathrm{ng} / \mathrm{band}$ concentrations $(n=6)$ of DLFX. Intermediate/inter-day precision was obtained by the analysis of samples on three consecutive days at 75, 300 and $400 \mathrm{ng} / \mathrm{band}$ concentrations $(n=6)$ of DLFX for the RP-HPTLC method. The intermediate precision of the NP-HPTLC method was also determined on three consecutive days at 150, 300 and $400 \mathrm{ng} / \mathrm{band}$ concentrations $(n=6)$ of DLFX. According to ICH guidelines for precision measurement, at least three different concentrations within the linearity range should be analyzed [31]. Therefore, the proposed concentrations were selected for precision evaluation. 
Method robustness was found out by making a small deliberate variation in the composition of the mobile phase during DLFX analysis. For the green RP-HPTLC method, the original mobile phase composition of ethanol:water:ammonia solution $(5: 4: 2, v / v / v)$ was changed to ethanol:water:ammonia solution $(5.2: 3.8: 2, v / v / v)$ and ethanol:water:ammonia solution $(4.8: 4.2: 2, v / v / v)$ for the positive and negative level, respectively. For the NP-HPTLC method, the original mobile phase composition of ethyl acetate: methanol: ammonia solution $(5: 4: 2, v / v / v)$ was changed to ethyl acetate: methanol: ammonia solution (5.2:3.8:2, v/v/v) and ethyl acetate: methanol: ammonia solution $(4.8: 4.2: 2, v / v / v)$ for the positive and negative level, respectively.

Method sensitivity was found out in terms of "limit of detection (LOD) and limit of quantification (LOQ)" using "standard deviation (SD)" technique. The "LOD and LOQ" values of DLFX for both methods were calculated using Equations (1) and (2), respectively:

$$
\begin{aligned}
& \mathrm{LOD}=3.3 \times \frac{\mathrm{SD}}{\mathrm{S}} \\
& \mathrm{LOQ}=10 \times \frac{\mathrm{SD}}{\mathrm{S}}
\end{aligned}
$$

where, $\mathrm{S}=$ slope of the CC of DLFX.

The method specificity for both methods was determined by comparing the $\mathrm{R}_{\mathrm{f}}$ values and UV absorption spectra of DLFX in SLNs samples with that of the standard DLFX.

For the analysis of DLFX in commercial tablets and SLNs the samples of commercial tablets and in-house developed SLNs were applied on TLC plates and HPTLC-densitograms were recorded using the same experimental procedures as described for the determination of standard DLFX. The HPTLC area of DLFX in tablet dosage forms and in-house developed SLNs was determined. The amount of DLFX in both formulations was calculated using the CC of DLFX for both methods.

\section{Results and Discussion}

\subsection{Preparation and Characterization of DLFX-Loaded SLNS}

DLFX-loaded SA-CS-SLNs were obtained using a "single emulsion solvent evaporation method" [32]. The composition of SA-CS-SLNs and their characterization parameters are summarized in Table 1. The particle size and polydispersity index of SA-CS-SLNs were found as $368.0 \pm 5.2 \mathrm{~nm}$ and $0.2 \pm 0.0$, respectively. The zeta potential of SA-CS-SLNs was found to be $19.2 \pm 1.4 \mathrm{mV}$. The entrapment efficiency of SA-CS-SLNs was obtained as $80.4 \pm 3.1 \%$. These results indicated that the SA-CS-SLNs of DLFX was well prepared in the laboratory.

Table 1. The composition and characterization data of DLFX-loaded SA-CS-SLNs $(n=3)$.

\begin{tabular}{cccc}
\hline \multicolumn{2}{c}{ Formulation Composition } & \multicolumn{2}{c}{ Characterization Parameter } \\
\hline DLFX $(\mathrm{mg})$ & 10 & Particle size \pm SD $(\mathrm{nm})$ & $368.0 \pm 5.2$ \\
SA $(\mathrm{mg})$ & 400 & Polydispersity index \pm SD & $0.2 \pm 0.0$ \\
CS $(\mathrm{mg})$ & 10 & Zeta potential \pm SD $(\mathrm{mV})$ & $19.2 \pm 1.4$ \\
Pluronic F-127 $(\mathrm{mg})$ & 50 & Entrapment efficiency \pm SD $(\%)$ & $80.4 \pm 3.1$ \\
\hline
\end{tabular}

\subsection{Method Development}

A literature survey indicated not a single RP-HPTLC or NP-HPTLC method for the determination of DLFX in SLNs. Therefore, the present work was aimed to develop a green RP-HPTLC method for the determination of DLFX in commercial tablets and in-house developed SLNs in comparison with a NP-HPTLC method. In the green RP-HPTLC method, the mobile phase was obtained by the simple mixture of ethanol, water and ammonia solution. However, in the case of the NP-HPTLC method, the mobile phase was prepared by mixing ethyl acetate, methanol and ammonia solution. The use of the RP-HPTLC method presents several advantages over NP-HPTLC which include avoidance of 
the non-polar fractions from the sample in the TLC plates, avoidance of the interference due to the presence of impurities, formation of compact spot and detection clarity [16,33]. The green RP-HPTLC method for the determination of DLFX will also decrease the chances of toxicity to the environment compared with the NP-HPTLC method [26,27].

In this study, various compositions of ethanol:water:ammonia solution such as 6:4:1 (v/v/v), 5:5:1 $(v / v / v), 4: 5: 2(v / v / v), 4: 4: 3(v / v / v)$ and 5:4:2 (v/v/v) were studied as the mobile phase for the development of a suitable band for RP-HPTLC-densitometric analysis of DLFX. The green mobile phase was developed using chamber saturation conditions (Figure 1).

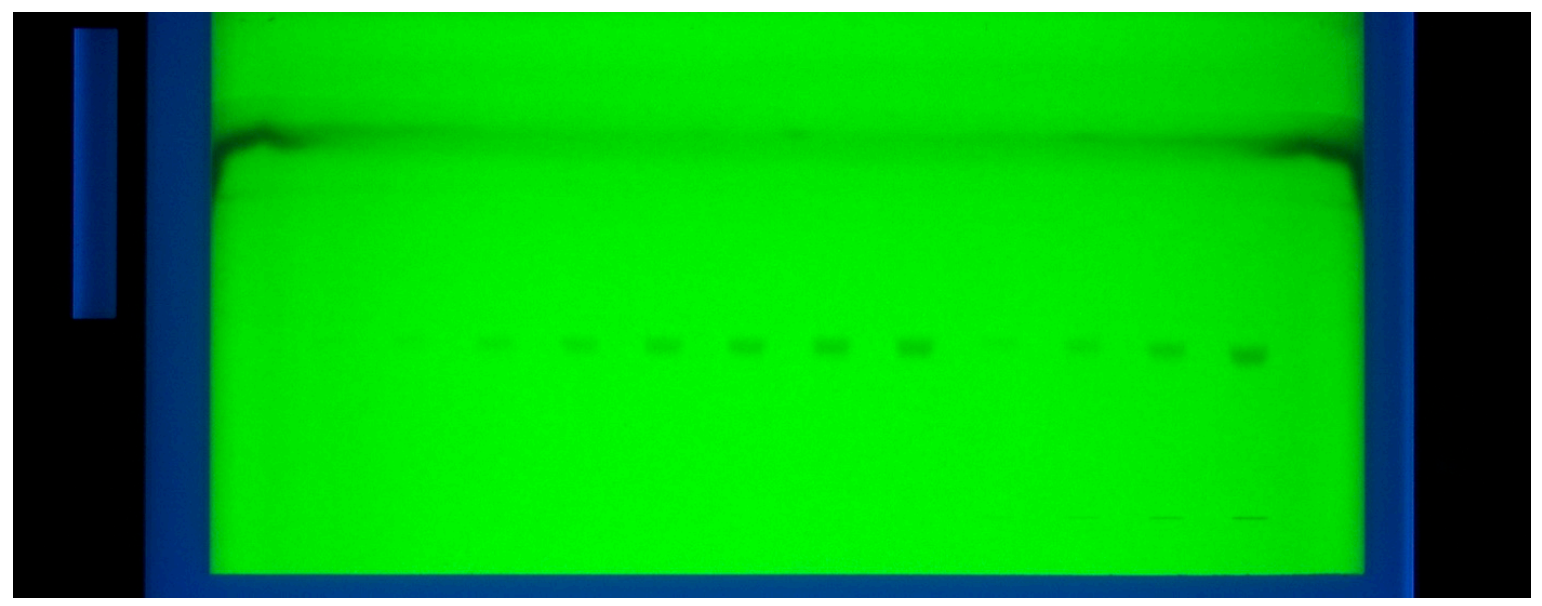

Figure 1. Pictorial diagram for the developed TLC plate for DLFX analysis.

The combination of ethanol:water:ammonia solutions such as 6:4:1 (v/v/v) and 5:5:1 (v/v/v) resulted in the presentation of poor densitometric peak with a poor symmetry of DLFX. However, the combinations of ethanol:water:ammonia solution such as 4:5:2 (v/v/v) and 4:4:3 (v/v/v) presented good densitometric peaks but the peak symmetry of DLFX was poor. Out of the various ethanol, water and ammonia solution compositions studied, the ternary mixture of ethanol:water:ammonia solution 5:4:2 (v/v/v) gave a well-resolved and compact peak of DLFX at $R_{f}=0.84 \pm 0.01$ (Figure 2).

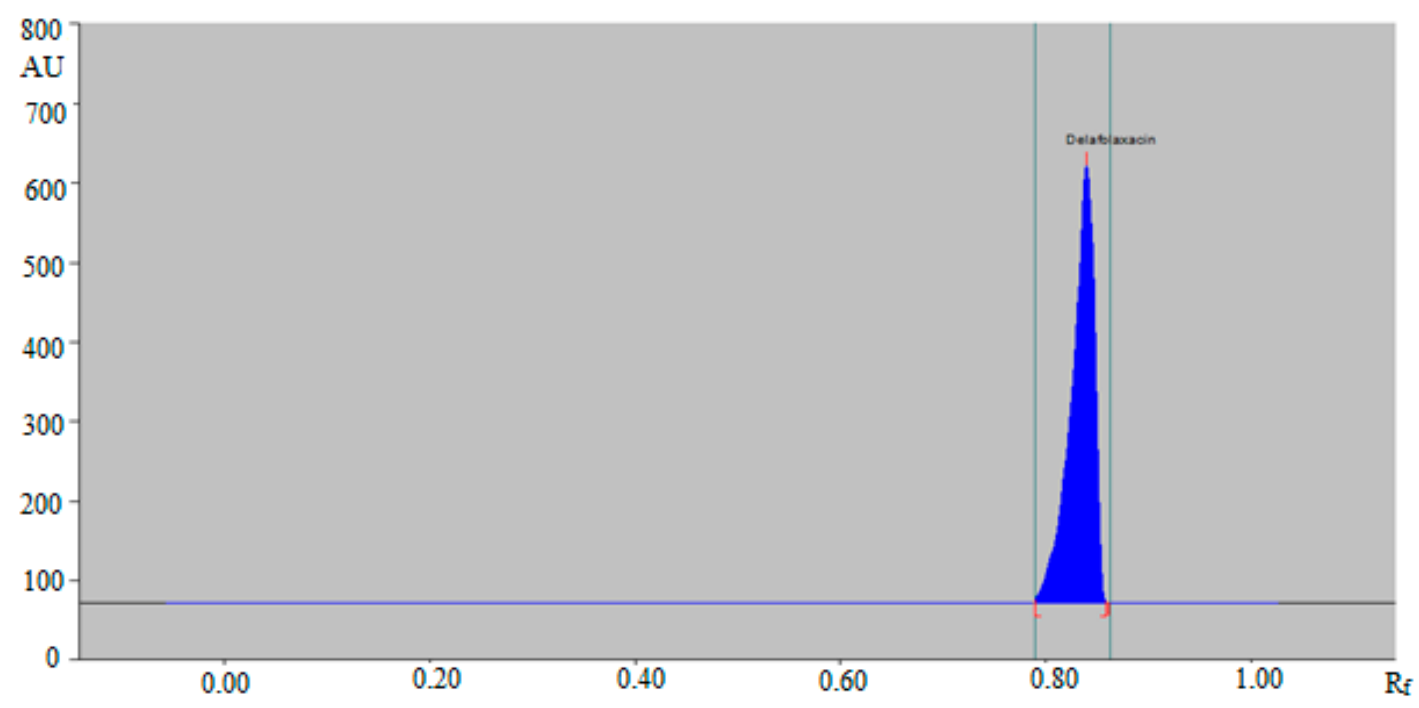

Figure 2. HPTLC chromatogram of standard DLFX by green RP-HPTLC method.

Hence, the ternary mixture of ethanol:water:ammonia solution 5:4:2 (v/v/v) was chosen as the mobile phase for the determination of DLFX in commercial tablets and in-house developed SLNs 
using the green RP-HPTLC method. Similarly, various compositions of ethyl acetate: methanol: ammonia solution such as 6:4:1 (v/v/v), 5:5:1 (v/v/v), 4:5:2 (v/v/v), 4:4:3 (v/v/v) and 5:4:2 (v/v/v) were studied as the mobile phase for the development of a suitable band for NP-HPTLC-densitometric analysis of DLFX. The combinations of ethyl acetate: methanol: ammonia solution such as 6:4:1 (v/v/v), 5:5:1 $(v / v / v), 4: 5: 2(v / v / v)$ and 4:4:3 (v/v/v) gave the same results as recorded for the green RP-HPTLC method. The NP-HPTLC mobile phase was also developed using chamber saturation conditions. Out of various compositions of ethyl acetate, methanol and ammonia solution studied, the ternary mixture of ethyl acetate: methanol: ammonia solution 5:4:2 (v/v/v) gave a well-resolved and compact peak of DLFX at $R_{\mathrm{f}}=0.44 \pm 0.01$ (Figure 3).

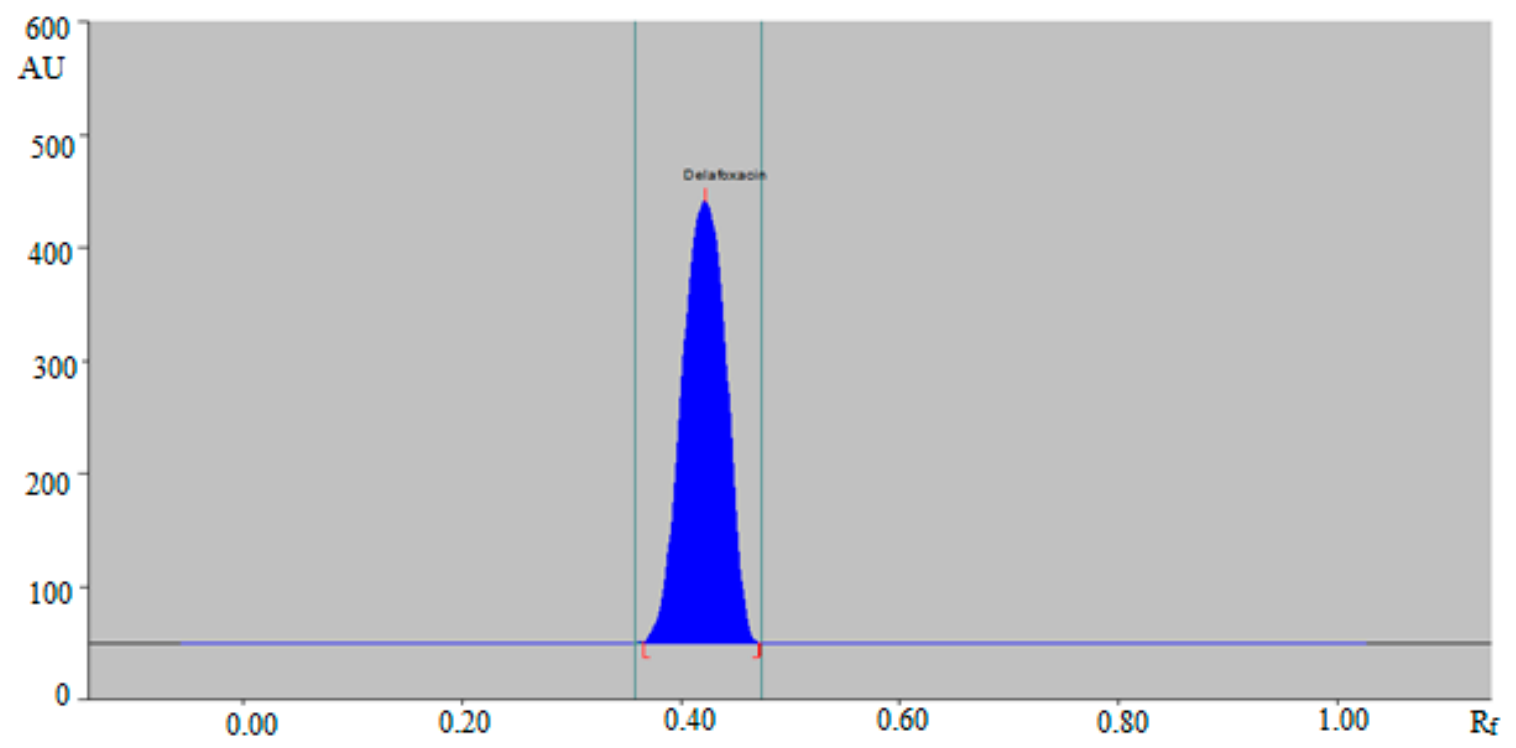

Figure 3. HPTLC chromatogram of standard DLFX by NP-HPTLC method.

Hence, the ternary mixture of ethyl acetate: methanol: ammonia solution 5:4:2 (v/v/v) was chosen as the mobile phase for the determination of DLFX in commercial tablets and in-house developed SLNs using the NP-HPTLC method. The bands spectra for both methods were recorded densitometrically and maximum HPTLC response under reflectance/absorbance mode was observed at $\lambda_{\max }=295 \mathrm{~nm}$ for both methods. Therefore, all analyses of DLFX were carried out at $295 \mathrm{~nm}$ for both methods.

\subsection{Method Validation} Table 2.

The results for linear regression analysis of CC of DLFX for both methods are summarized in

The CC of DLFX was found linear in concentration range of 25-1000 ng/band for the green RP-HPTLC method. However, the CC of DLFX was found linear in concentration range of 50-600 ng/band for the NP-HPTLC method. The data for both methods showed good linear relationship between the concentration and HPTLC area (Table 2). The determination coefficient $\left(\mathrm{R}^{2}\right)$ values for DLFX was regressed as 0.9996 and 0.9995 for the green RP-HPTLC and NP-HPTLC methods, respectively. 
Table 2. Linear regression data for the calibration curve of DLFX for green RP-HPTLC and NP-HPTLC methods $(n=6)$.

\begin{tabular}{ccc}
\hline Parameters & Green RP-HPTLC & NP-HPTLC \\
\hline Linearity range (ng/band) & $25-1000$ & $50-600$ \\
Regression equation & $\mathrm{Y}=33.62 \mathrm{x}-184.11$ & $\mathrm{Y}=23.90 \mathrm{x}+201.55$ \\
$\mathrm{R}^{2}$ & 0.9996 & 0.9995 \\
Slope $\pm \mathrm{SD}$ & $33.62 \pm 1.62$ & $23.90 \pm 0.86$ \\
Intercept $\pm \mathrm{SD}$ & $184.11 \pm 4.52$ & $201.55 \pm 6.73$ \\
Standard error of slope & 0.66 & 0.35 \\
Standard error of intercept & 1.84 & 2.74 \\
$95 \%$ confidence interval of slope & $30.77-36.46$ & $22.38-25.41$ \\
$95 \%$ confidence interval of intercept & $176.16-192.05$ & $189.72-213.37$ \\
LOD \pm SD (ng/band) & $8.54 \pm 0.22$ & $17.31 \pm 0.51$ \\
LOQ \pm SD (ng/band) & $25.62 \pm 0.66$ & $51.93 \pm 1.53$ \\
\hline
\end{tabular}

The $\mathrm{R}^{2}$ values for both methods were highly significant $(p<0.05)$. The linear regression equation for the green RP-HPTLC method was computed as $Y=33.62 x-184.11$, in which $Y$ is the measured peak area and $x$ represents the concentration of DLFX. The linear regression equation for the NP-HPTLC method was computed as $Y=23.90 x+201.55$. Overall, the linear regression analysis suggested good linearity of both the methods. Method accuracy for both methods was computed as \% recovery. The results of accuracy evaluation for both methods are presented in Table 3.

Table 3. Accuracy data for green RP-HPTLC and NP-HPTLC methods $(n=6)$.

\begin{tabular}{|c|c|c|c|c|}
\hline Conc. (ng/band) & Theoretical Content (ng) & Conc. Found (ng) \pm SD & Recovery (\%) & RSD (\%) \\
\hline \multicolumn{5}{|c|}{ Green RP-HPTLC method } \\
\hline 75 & 75 & $73.8 \pm 1.4$ & 98.4 & 1.89 \\
\hline 300 & 300 & $296.9 \pm 3.8$ & 98.9 & 1.29 \\
\hline 400 & 400 & $402.8 \pm 7.0$ & 100.7 & 1.74 \\
\hline 500 & 500 & $505.1 \pm 7.5$ & 101.0 & 1.48 \\
\hline \multicolumn{5}{|c|}{ NP-HPTLC method } \\
\hline 150 & 150 & $144.2 \pm 2.5$ & 96.1 & 1.73 \\
\hline 300 & 300 & $290.1 \pm 4.8$ & 96.7 & 1.66 \\
\hline 400 & 400 & $383.7 \pm 9.8$ & 95.9 & 2.57 \\
\hline 500 & 500 & $480.2 \pm 12.7$ & 96.0 & 2.65 \\
\hline
\end{tabular}

The \% recovery of DLFX for the green RP-HPTLC method was computed as $98.4-101.0 \%$. The $\%$ RSD in the accuracy of DLFX for the green RP-HPTLC method was computed as $1.29-1.89 \%$. The $\%$ recovery of DLFX for the NP-HPTLC method was computed as $95.9-96.7 \%$. The $\%$ RSD in the accuracy of DLFX for the NP-HPTLC method was computed as $1.73-2.65 \%$. The $\%$ recovery of DLFX using various derivative spectrometry methods has been reported as $97.5-100.7 \%$ in literature [11]. The recorded \% recovery of DLFX (98.4-101.0\%) using the green RP-HPTLC method was better than the reported derivative spectrometry method. However, the recorded \% recovery of DLFX (95.9-96.7\%) using the NP-HPTLC method was much lower than reported derivative spectrometry method. The computed values of accuracy within the limit of $100 \pm 2 \%$ and $\%$ RSD $\pm 2 \%$ suggested that the green RP-HPTLC method was more accurate for the determination of DLFX compared with the NP-HPTLC method.

Method precision for both methods was computed as \% RSD. The results of precision for both methods are listed in Table 4 . The \% RSD values of the green RP-HPTLC method for the repeatability and intermediate precision were computed as $1.14-1.60 \%$ and $1.26-1.70 \%$, respectively. The $\%$ RSD values of the NP-HPTLC method for the repeatability and intermediate precision were computed as 
$1.72-2.45 \%$ and $1.84-2.61 \%$, respectively. The \% RSD values using various derivative spectrometry methods for the repeatability and intermediate precision have been reported as $0.45-1.92 \%$ and $0.37-1.54 \%$, respectively in literature [11]. The recorded \% RSD values using the green RP-HPTLC method for the repeatability and intermediate precision were similar to reported derivative spectrometry method. However, the recorded \% RSD values using the NP-HPTLC method for the repeatability and intermediate precision were much higher compared to reported derivative spectrometry method. The computed values of \% RSD within the limit of $\pm 2 \%$ indicated that the green RP-HPTLC method was more precise for the determination of DLFX compared with the NP-HPTLC method.

Table 4. Precision data for the green RP-HPTLC and NP-HPTLC methods $(n=6)$.

\begin{tabular}{|c|c|c|c|c|c|c|}
\hline \multirow{2}{*}{$\begin{array}{c}\text { Conc. } \\
\text { (ng/band) }\end{array}$} & \multicolumn{3}{|c|}{ Repeatability (Intraday Precision) } & \multicolumn{3}{|c|}{ Intermediate Precision (Interday) } \\
\hline & Area \pm SD & Standard Error & RSD (\%) & Area \pm SD & Standard Error & RSD (\%) \\
\hline \multicolumn{7}{|c|}{ Green RP-HPTLC method } \\
\hline 75 & $2316.7 \pm 29.2$ & 11.9 & 1.26 & $2442.2 \pm 32.4$ & 13.2 & 1.32 \\
\hline 300 & $9776.1 \pm 112.2$ & 45.8 & 1.14 & $9598.2 \pm 121.8$ & 49.7 & 1.26 \\
\hline 400 & $13,676.3 \pm 219.3$ & 89.5 & 1.60 & $13,754.6 \pm 234.9$ & 95.9 & 1.70 \\
\hline \multicolumn{7}{|c|}{ NP-HPTLC method } \\
\hline 150 & $3961.6 \pm 69.7$ & 28.4 & 1.75 & $4088.4 \pm 75.3$ & 30.7 & 1.84 \\
\hline 300 & $7345.1 \pm 126.7$ & 51.7 & 1.72 & $7415.3 \pm 137.2$ & 56.0 & 1.85 \\
\hline 400 & $9826.7 \pm 241.6$ & 98.6 & 2.45 & $9754.6 \pm 255.5$ & 104.3 & 2.61 \\
\hline
\end{tabular}

Results of method robustness for both methods are listed in Table 5. The \% RSD values after introducing small deliberate changes in the composition of mobile phase were recorded as $1.08-1.21 \%$ for the green RP-HPTLC method. The $\mathrm{R}_{\mathrm{f}}$ value for DLFX after this change was recorded in the range of 0.83-0.85 for the green RP-HPTLC method. However, the \% RSD values were recorded as $1.66-1.87 \%$ for the NP-HPTLC method. The $\mathrm{R}_{\mathrm{f}}$ value for DLFX after this change was recorded in the range of 0.43-0.45 for the NP-HPTLC method. The small variations in $\mathrm{R}_{\mathrm{f}}$ values of DLFX and lower \% RSD values indicated that both methods were robust for the determination of DLFX. However, the green RP-HPTLC method was more robust than the NP-HPTLC method.

Table 5. Robustness data for green the RP-HPTLC and NP-HPTLC methods $(n=6)$.

\begin{tabular}{|c|c|c|c|c|c|c|}
\hline \multirow{2}{*}{$\begin{array}{c}\text { Conc. } \\
\text { (ng/band) }\end{array}$} & \multicolumn{3}{|c|}{$\begin{array}{c}\text { Mobile Phase Composition } \\
\text { (ethanol:water:ammonia Solution) }\end{array}$} & \multicolumn{3}{|c|}{ Results } \\
\hline & Original & Used & & Area \pm SD & $\%$ RSD & $\mathbf{R}_{\mathrm{f}}$ \\
\hline \multicolumn{7}{|c|}{ Green RP-HPTLC method } \\
\hline \multirow{3}{*}{300} & \multirow{3}{*}{$5: 4: 2$} & 5.2:3.8:2 & +0.2 & $9614.8 \pm 106.9$ & 1.11 & 0.83 \\
\hline & & $5: 4: 2$ & 0.0 & $9589.8 \pm 104.1$ & 1.08 & 0.84 \\
\hline & & 4.8:4.2:2 & -0.2 & $9454.3 \pm 114.8$ & 1.21 & 0.85 \\
\hline \multicolumn{7}{|c|}{ NP-HPTLC method } \\
\hline \multicolumn{7}{|c|}{ Mobile phase composition (ethyl acetate: methanol: ammonia solution) } \\
\hline \multirow{3}{*}{300} & \multirow{3}{*}{$5: 4: 2$} & $5.2: 3.8: 2$ & +0.2 & $7374.6 \pm 122.7$ & 1.66 & 0.43 \\
\hline & & $5: 4: 2$ & 0.0 & $7298.4 \pm 116.5$ & 1.59 & 0.44 \\
\hline & & $4.8: 4.2: 2$ & -0.2 & $7153.7 \pm 134.4$ & 1.87 & 0.45 \\
\hline
\end{tabular}

The method sensitivity for both methods was computed as "LOD and LOQ". The computed values of "LOD and LOD" for both methods are presented in Table 2. The "LOD and LOQ" values of the green RP-HPTLC method were computed as $8.54 \pm 0.22$ and $25.62 \pm 0.66 \mathrm{ng} / \mathrm{band}$, respectively for DLFX. However, the "LOD and LOQ" values of the NP-HPTLC method were computed as $17.31 \pm 0.51$ and $51.93 \pm 1.53 \mathrm{ng} / \mathrm{band}$, respectively for DLFX. The computed values of "LOD and LOQ" suggested that both methods were sensitive enough for the determination of DLFX. However, the green RP-HPTLC method was more sensitive than the NP-HPTLC method. 
Method specificity and the peak purity of DLFX for both methods were obtained by comparing the overlaid spectra of DLFX in SLN samples and standard DLFX. The overlaid spectra of standard DLFX and DLFX in in-house developed SLNs are presented in Figure 4. The maximum densitometric response of DLFX in standard and SLNs was found at $\lambda_{\max }=295 \mathrm{~nm}$ for both methods. The similar HPTLC spectra, $R_{f}$ values and $\lambda_{\max }$ of DLFX in standard and SLNs suggested the specificity and peak purity of both methods.

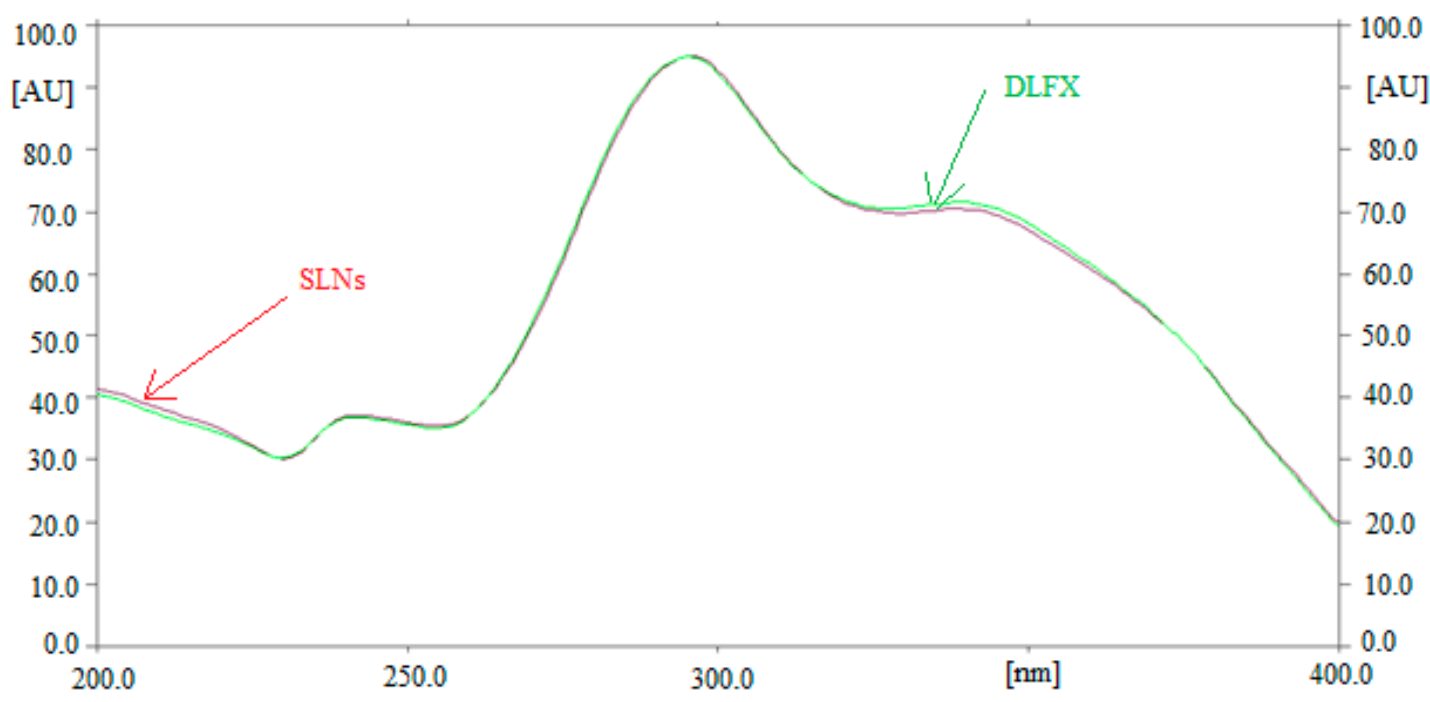

Figure 4. Overlaid UV absorption spectra of standard DLFX and in-house developed SLNs.

\subsection{Determination of DLFX in Commercial Tablets and SLNS}

A literature survey indicated not a single green RP-HPTLC method for the determination of DLFX in pharmaceutical products and biological samples. Hence, a green RP-HPTLC method could be an alternative approach for the determination of DLFX in pharmaceutical products compared with a NP-HPTLC method. The HPTLC peak of DLFX from commercial tablet and SLNs was identified by comparing their single TLC spot at $R_{f}=0.84 \pm 0.01$ with that of standard DLFX for the green RP-HPTLC method. The representative HPTLC chromatogram of DLFX in in-house developed SLNs for the green RP-HPTLC method is presented in Figure 5, which is found to be similar to that of standard DLFX.

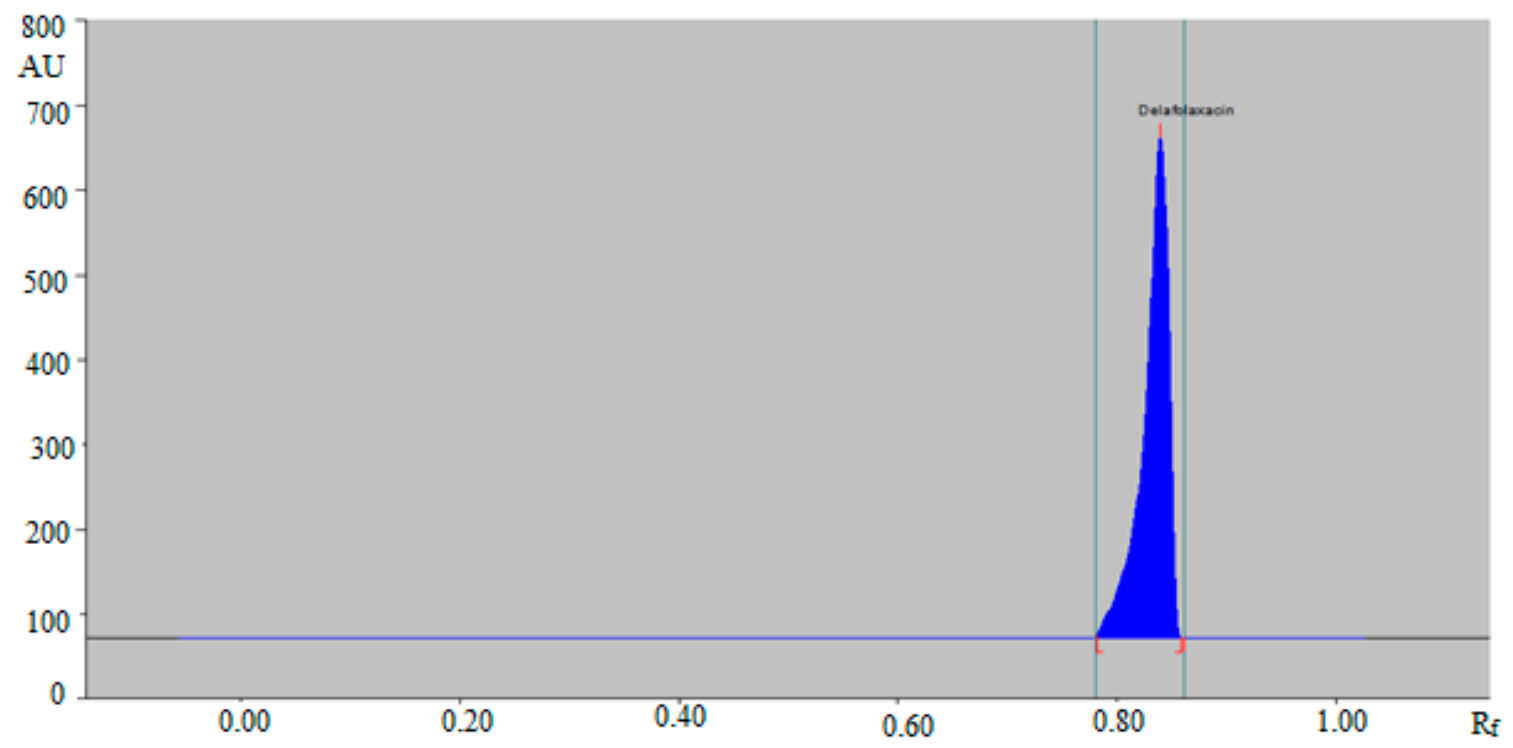

Figure 5. HPTLC chromatogram of DLFX in in-house developed SLNs by the green RP-HPTLC method. 
The HPTLC peak of DLFX from commercial tablets and SLNs was also identified by comparing their single TLC spots at $\mathrm{R}_{\mathrm{f}}=0.44 \pm 0.01$ with that of standard DLFX for the NP-HPTLC method. The representative HPTLC chromatogram of DLFX in in-house developed SLNs for the NP-HPTLC method is presented in Figure 6, which is also similar with that of standard DLFX. The amount of DLFX in commercial tablets and in-house developed SLNs was computed by the CC of DLFX. The results of the determination of DLFX in commercial tablets SLNs for both methods are listed in Table 6.

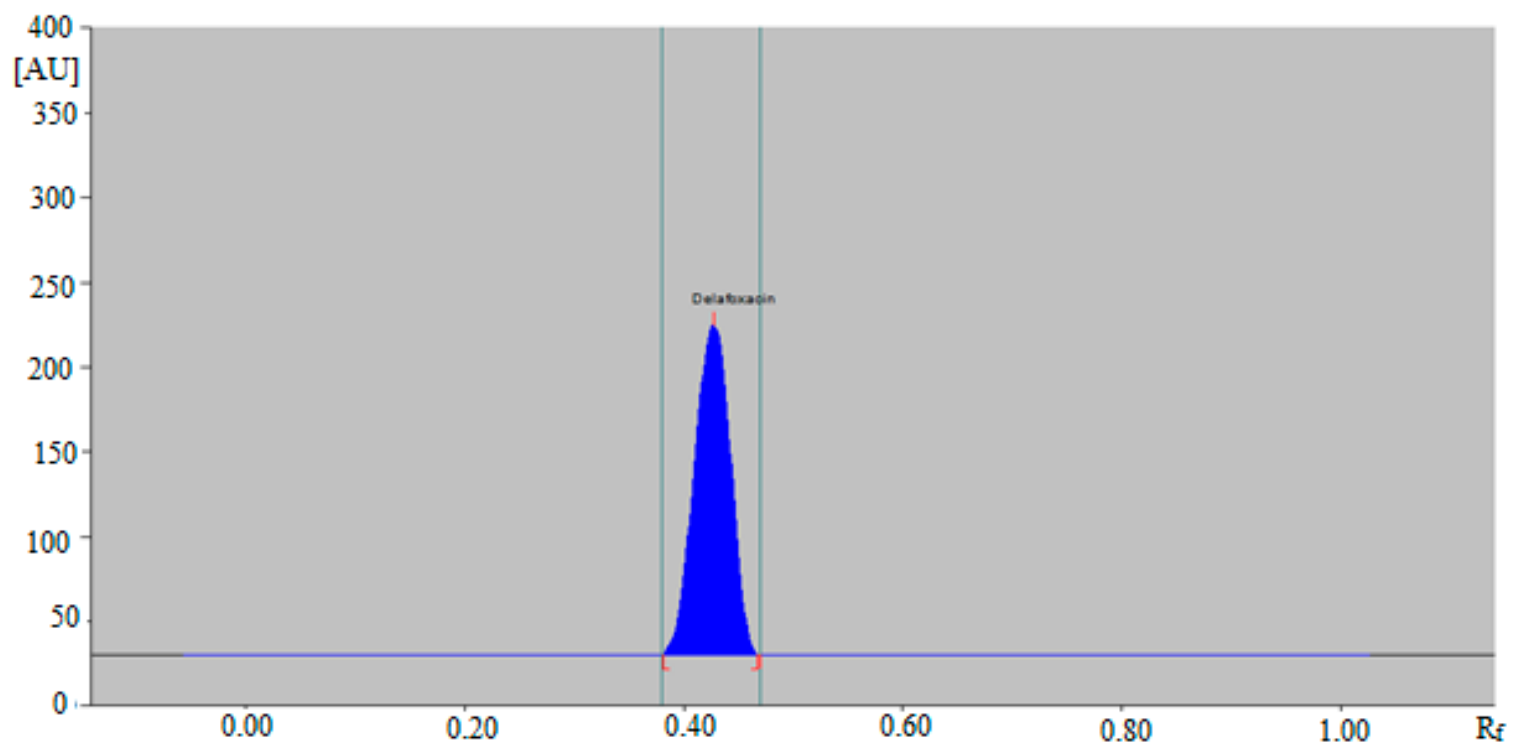

Figure 6. HPTLC chromatogram of DLFX in in-house developed SLNs by NP-HPTLC method.

Table 6. Assay of DLFX in marketed tablets and SLNs formulation by the green RP-HPTLC and NP-HPTLC methods $(n=3)$.

\begin{tabular}{|c|c|c|c|}
\hline Samples & Theoretical Content (mg) & Content Found $(\mathrm{ng}) \pm \mathrm{SD}$ & Assay (\%) \\
\hline & \multicolumn{3}{|c|}{ Green RP-HPTLC method } \\
\hline Marketed tablets & 50 & $49.1 \pm 1.0$ & 98.2 \\
\hline \multirow[t]{2}{*}{ SLNs } & 50 & $50.5 \pm 1.1$ & 101.0 \\
\hline & \multicolumn{3}{|c|}{ NP-HPTLC method } \\
\hline Marketed tablets & 50 & $47.2 \pm 1.2$ & 94.4 \\
\hline SLNs & 50 & $47.5 \pm 1.3$ & 95.0 \\
\hline
\end{tabular}

The amount of DLFX in commercial tablets was computed as $49.1 \pm 1.0 \mathrm{mg}$ out of $50 \mathrm{mg}$ of theoretical DLFX using the green RP-HPTLC method. However, the amount of DLFX in in-house developed SLNs was computed as $50.5 \pm 1.1 \mathrm{mg}$ compared with $50 \mathrm{mg}$ of theoretical DLFX using the green RP-HPTLC method. The amount of DLFX in commercial tablets was found as $47.2 \pm 1.2 \mathrm{mg}$ out of $50 \mathrm{mg}$ of theoretical DLFX using the NP-HPTLC method. However, the amount of DLFX in in-house developed SLNs was found as $47.5 \pm 1.3 \mathrm{mg}$ out of $50 \mathrm{mg}$ of theoretical DLFX using the NP-HPTLC method. The \% assay of DLFX in commercial tablets and in-house developed SLNs was obtained as 98.2 and 101.0\%, respectively using the green RP-HPTLC method. However, the \% assay of DLFX in commercial tablets and in-house developed SLNs was obtained as 94.4 and 95.0\%, respectively using the NP-HPTLC method. The $\%$ assay of DLFX within the range of $\pm 2 \%$ by a green RP-HPTLC method suggested that the green RP-HPTLC method can be successfully applied for the pharmaceutical analysis of DLFX in commercial products containing DLFX as an active drug compared with the NP-HPTLC method. Based on accuracy, precision, robustness, sensitivity and pharmaceutical assay, the proposed green RP-HPTLC method was found superior than the NP-HPTLC method for the determination of DLFX in pharmaceutical products. 


\section{Conclusions}

A green RP-HPTLC method was developed and validated for the determination of DLFX in pure form, commercial tablets and in-house developed SLNs compared with a NP-HPTLC method. SLNs of DLFX was prepared using a "single emulsion and solvent evaporation method" and characterized for particle size, polydispersity, zeta potential and entrapment efficiency. Both the methods were validated for the determination of DLFX. However, the green RP-HPTLC method was found more accurate, precise, robust and sensitive for the determination of DLFX compared with a NP-HPTLC method. Both the methods were successfully applied for the analysis of DLFX in commercial tablets and SLNs. The green RP-HPTLC method reproduced the pharmaceutical assay results within the prescribed limit compared with the NP-HPTLC method. Overall, the green RP-HPTLC method was found superior to the NP-HPTLC method for the pharmaceutical analysis of DLFX in commercial tablets and in-house developed NPs. Therefore, the green RP-HPTLC method can be successfully utilized for the pharmaceutical assay of DLFX in a wide variety of commercial formulations containing DLFX as an active constituent.

Author Contributions: Conceptualization, supervision-P.A.; Methodology-E.E., M.I., G.A.E.M., F.S. and M.K.A.; Validation-A.I.F., M.H.A. and F.S.; Data curation-A.I.F., M.H.A. and P.A.; Funding acquisition-E.E.; Project administration-P.A.; Software-M.K.A., M.I. and F.S.; Writing original draft-F.S.; Writing-review and editing-M.I., E.E. and P.A. All authors have read and agreed to the published version of the manuscript.

Funding: This research was funded by the Deanship of Scientific Research at King Saud University, Riyadh, Saudi Arabia via grant number RG-1435-072 and article processing charge (APC) was also supported by the Deanship of Scientific Research.

Acknowledgments: The authors would like to extend their sincere appreciation to the Deanship of Scientific Research at King Saud University, Riyadh, Saudi Arabia for funding this work through the research group project number RG-1435-072.

Conflicts of Interest: The authors report no conflict of interest associated with this manuscript.

\section{References}

1. Falcone, M.; Concia, E.; Giusti, M.; Mazzone, A.; Santini, C.; Stefani, S.; Violi, F. Acute bacterial skin and skin structure infections in internal medicine wards: Old and new drugs. Intern. Emerg. Med. 2016, 11, $637-648$. [CrossRef] [PubMed]

2. Ray, G.T.; Suaya, J.A.; Baxter, R. Incidence, microbiology, and patient characteristics of skin and soft-tissue infections in a U.S. population: A retrospective population based study. BMC Infect. Dis. 2013, 13, E252. [CrossRef] [PubMed]

3. Bassetti, M.; Della Siega, P.; Pecori, D.; Scarparo, C.; Righi, E. Delafloxacin for the treatment of respiratory and skin infections. Expert. Opin. Investig. Drugs 2015, 24, 433-442. [CrossRef] [PubMed]

4. Cho, J.C.; Crotty, M.P.; White, B.P.; Worley, M.V. What is old is new again: Delafloxacin, a modern fluoroquinolone. Pharmacotherapy 2018, 38, 108-121. [CrossRef]

5. Markham, A. Delafloxacin: First global approval. Drugs 2017, 77, 1481-1486. [CrossRef]

6. Hatoum, H.T.; Akhras, K.S.; Lin, S.J. The attributable clinical and economic burden of skin and skin structure infections in hospitalized patients: A matched cohort study. Diagn. Microbiol. Infect. Dis. 2009, 64, 305-310. [CrossRef]

7. Thabit, A.K.; Crandon, J.L.; Nicolau, D.P. Pharmacodynamic and pharmacokinetic profiling of delafloxacin in a murine lung model against community-acquired respiratory tract pathogens. Int. J. Antimicrob. Agents 2016, 48, 535-541. [CrossRef] [PubMed]

8. Bassetti, M.; Pecori, D.; Cojutti, P.; Righi, E.; Pea, F. Clinical and pharmacokinetic drug evaluation of delafloxacin for the treatment of acute bacterial skin and skin structure infections. Expert Opin. Drug. Metab. Toxicol. 2017, 13, 1193-1200. [CrossRef] [PubMed]

9. Shiu, J.; Ting, G.; Kiang, T.K. Clinical pharmacokinetics and pharmacodynamics of delafloxacin. Eur. J. Drug Metab. Pharmacokinet. 2019, 44, 305-317. [CrossRef] [PubMed] 
10. Iqbal, M.; Ezzeldin, E.; Harqash, R.N.; Anwer, M.K.; Azam, F. Development and validation of a novel UPLC-MS/MS method for quantification of delafloxacin in plasma and aqueous humour for pharmacokinetic analyses. J. Chromatogr. B 2020, 1138, E121961. [CrossRef] [PubMed]

11. Dhangar, K.R.; Shirkhedkar, A.A. Estimation of delafloxacin using derivative spectrophotometry and area under curve in bulk material and in laboratory mixture. J. Pharm. Technol. Res. Manag. 2016, 4, 81-97. [CrossRef]

12. Alam, P.; Iqbal, M.; Ezzeldin, E.; Khalil, N.Y.; Foudah, A.I.; Alqarni, M.H.; Shakeel, F. Simple and accurate HPTLC-densitometric method for quantification of delafloxacin (a novel fluoroquinolone antibiotic) in plasma samples: Application to pharmacokinetic study in rats. Antiobiotics 2020, 9, 134. [CrossRef] [PubMed]

13. Hoover, R.; Hunt, T.; Benedict, M.; Paulson, S.K.; Lawrence, L.; Cammarata, S.; Sun, E. Single and multiple ascending-dose studies of oral delafloxacin: Effects of food, sex, and age. Clin. Ther. 2016, 38, 39-52. [CrossRef] [PubMed]

14. Hoover, R.; Alcorn, H., Jr.; Lawrence, L.; Paulson, S.K.; Quintas, M.; Cammarata, S.K. Pharmacokinetics of intravenous delafloxacin in patients with end-stage renal disease. J. Clin. Pharmacol. 2018, 58, 913-919. [CrossRef]

15. Hoover, R.K.; Alcorn, H., Jr.; Lawrence, L.; Paulson, S.K.; Quintas, M.; Cammarata, S.K. Delafloxacin pharmacokinetics in subjects with varying degrees of renal function. J. Clin. Pharmacol. 2018, 58, 814-822. [CrossRef]

16. Alam, P.; Ezzeldin, E.; Iqbal, M.; Anwer, M.K.; Mostafa, G.A.E.; Alqarni, M.H.; Foudah, A.I.; Shakeel, F. Ecofriendly densitometric RP-HPTLC method for determination of rivaroxaban in nanoparticle formulations using green solvents. RSC Adv. 2020, 10, 2133-2140. [CrossRef]

17. Haq, N.; Shakeel, F.; Alanazi, F.; Alshora, D.H.; Ibrahim, M.A. Development and validation of a green RP-HPLC method for the analysis of rosuvastatin: A step towards making liquid chromatography environmentally benign. Green Process. Synth. 2018, 7, 160-169. [CrossRef]

18. Abou-Taleb, N.H.; Al-Enany, N.M.; El-Sherbiny, D.T.; El-Subbagh, H.I. Digitally enhanced thin layer chromatography for simultaneous determination of norfloxacin tinidazole with the aid of Taguchi orthogonal array and desirability function approach: Greenness assessment by analytical eco-scale. J. Sep. Sci. 2020, 43, 1195-1202. [CrossRef]

19. Glazowska, J.; Kaminski, M.M.; Kaminski, M. Chromatographic separation, determination and identification of ecdysteroids: Focus on Maral root (Rhaponticum carthamoides, Leuzea carthamoides). J. Sep. Sci. 2018, 41, 4304-4314. [CrossRef]

20. Haq, N.; Iqbal, M.; Alanazi, F.K.; Alsarra, I.A.; Shakeel, F. Applying green analytical chemistry for rapid analysis of drugs: Adding health to pharmaceutical industry. Arabian J. Chem. 2017, 10, S777-S785. [CrossRef]

21. Ibrahim, F.A.; Elmansi, H.; Fathy, M.E. Green RP-HPLC method for simulatneous determination of moxifloxacin combinations: Investigation of the greenness for the proposed method. Microchem. J. 2019, 148, 151-161. [CrossRef]

22. Ostovan, A.; Ghaedi, M.; Arabi, M.; Yang, Q.; Li, J.; Chen, L. Hydrophilic Multitemplate molecularly imprinted biopolymers based on a green synthesis strategy for determination of B family vitamins. ACS Appl. Mater. Interfaces 2018, 10, 4140-4150. [CrossRef] [PubMed]

23. Haq, N.; Siddiqui, N.A.; Alam, P.; Shakeel, F.; Alanazi, F.K.; Alsarra, I.A. Estimation of sodium lauryl sulphate concentration in marketed formulations by stability-indicating 'green' planar chromatographic method. Chiang Mai J. Sci. 2018, 45, 1531-1542.

24. Youssof, A.M.E.; Salem-Bekhit, M.M.; Shakeel, F.; Alanazi, F.K.; Haq, N. Analysis of anti-neoplastic drug in bacterial ghost matrix, w/o/w double nanoemulsion and w/onanoemulsion by a validated 'green' liquid chromatographic method. Talanta 2016, 154, 292-298. [CrossRef]

25. Alsuwyeh, A.A.; Alanazi, F.; Shakeel, F.; Salem-Bekhit, M.M.; Haq, N. Estimation of anti-neoplastic drug doxorubicin in bacterial ghost matrix by new "environmentally benign" RP-HPLC method: A step towards sustainable development of pharmaceutical industry. Arab. J. Sci. Eng. 2018, 43, 181-190. [CrossRef]

26. Al-Alamein, A.M.A.; Abd El-Rahman, M.K.; Abdel-Moety, E.M.; Fawaz, E.M. Green HPTLC-densitometric approach for simultaneous determination and impurity-profiling of ebastine and phenylephrine hydrochloride. Microchem. J. 2019, 147, 1097-1102. [CrossRef] 
27. Rezk, M.R.; Monir, H.H.; Marzouk, H.M. Novel determination of a new antiviral combination; sofosbuvir and velpatasvir by high performance thin layer chromatographic method; application to real human samples. Microchem. J. 2019, 146, 828-834. [CrossRef]

28. Choma, I.M.; Olszowy, M.; Gnat, S. Determination of chlorogenic acid, polyphenols and antioxidants in green coffee by thin-layer chromatography, effect-directed analysis and dot blot- comparison to HPLC and spectrophotometry methods. J. Sep. Sci. 2019, 42, 1542-1549. [CrossRef]

29. Eman, A.A. Canagliflozocin stability study and eco-friendly chromatographic determination of its degradation products: A comparative study. J. Sep. Sci. 2018, 41, 822-830. [CrossRef]

30. Dong, S.; He, J.; Hou, H.; Shuai, Y.; Wang, Q.; Yang, W.; Sun, Z.; Li, Q.; Bi, K.; Liu, R. Quality assessment of Herba Leonuri based on the analysis of multiple components using normal- and reversed-phase chromatographic methods. J. Sep. Sci. 2017, 40, 4482-4494. [CrossRef]

31. International Conference on Harmonization (ICH). Q2 (R1): Validation of Analytical Procedures-Text and Methodology; International Conference on Harmonization (ICH): Geneva, Switzerland, 2005.

32. Anwer, M.K.; Iqbal, M.; Muharram, M.M.; Mohammad, M.; Ezzeldin, E.; Aldawsari, M.F.; Alalaiwe, A.; Imam, F. Development of lipomer nanoparticles for the enhancement of drug release, antimicrobial activity and bioavailability of delafloxacin. Pharmaceutics 2020, 12, 252. [CrossRef] [PubMed]

33. Ahmed, S.; Al-Rehaily, A.J.; Alam, P.; Alqahtani, A.S.; Hidayatullah, S.; Rehman, M.T.; Mothana, R.A.; Abbas, S.S.; Khan, M.U.; Khalid, J.M.; et al. Antidiabetic, antixidant, molecular docking and HPTLC analysis of miquelianin isolated from Euphorbia schimperi C. Presl. Saudi Pharm. J. 2019, 27, 655-663. [CrossRef] [PubMed]

(C) 2020 by the authors. Licensee MDPI, Basel, Switzerland. This article is an open access article distributed under the terms and conditions of the Creative Commons Attribution (CC BY) license (http://creativecommons.org/licenses/by/4.0/). 